\title{
Beyond Nicotine Gateway Hypothesis
}

\section{Somchai Bovornkitti*}

The Academy of science, Bangkok

\section{Introduction}

ISSN: 2689-2707

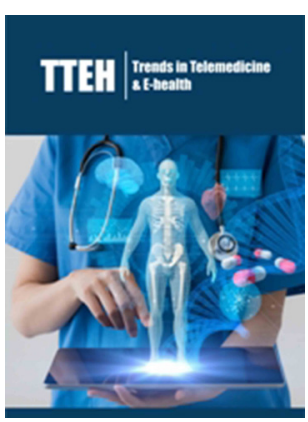

*Corresponding author: Somchai Bovornkitti, The Academy of science, Bangkok

Submission: 眥 December 4, 2019

Published: 此 December 09, 2019

Volume 2 - Issue 2

How to cite this article: Somchai Bovornkitti. Beyond Nicotine Gateway Hypothesis. Trends Telemed E-Health 2(2). TTEH. 000531. 2019. DOI: 10.31031/TTEH.2019.02.000531

Copyright@ Somchai Bovornkitti, This article is distributed under the terms of the Creative Commons Attribution 4.0 International License, which permits unrestricted use and redistribution provided that the original author and source are credited.
Psychological studies involving humans suggested that addiction is a form of learning and that relapse is a persistent memory of the drug experiences [1,2]. It is the gene transcription factor Cyclic AMP Response-Element-Binding protein (CREB) acting as a switch, converting short-term memory to long-term memory, referred to as the acetylation of chromatin structures [3]. For nicotine gateway hypothesis, data from a group of students, aged 15.7 to 34.2 years, showing the majority of cocaine users (75.2\%) were smoking during the month they began using cocaine [4], and the rate of cocaine dependence was highest (20.2\%) among users who started using cocaine after having smoked cigarettes, in contrast to dependence among persons who had begun using cocaine before they started smoking (6.3\%) and among those who had never smoked more than 100 cigarettes (10.1\%) [5].

Combining epidemiologic and biologic studies suggest a model in which nicotine exerts the priming effect on cocaine by means of HDAC inhibition and provide a molecular explanation of the unidirectional sequence of drug use observed in mice and in human populations. Nicotine acts as a gateway drug through global acetylation in the striatum, creating an environment primed for the induction of gene expression. Long-term exposure to nicotine presumably lessens constraints on dopaminergic neurons in the ventral tegmental area and leads to the enhanced release of dopamine [6].

Of note, the current debate about electronic e-cigarettes as a tool to stop smoking and reduce the harmful effects of combustible tobacco use in the population by eliminating some of the morbidity associated with combustible tobacco, is especially in regard to the heat-notburn electronic cigarettes while disregarding the nicotine-liquid electronic cigarettes per se [7]. Therefore, tobacco harm reduction by noncombustible tobacco cigarettes is beneficial and conclusively beyond nicotine gateway effect [8].

\section{"A gateway drug is a drug that lowers}

\section{the threshold for addiction to other agents"}

\section{References}

1. Kandel ER, Kandel DB (2014) A molecular basis for nicotine as a gateway drug. N Engl J Med 371(21): 2038-2039.

2. Wikler A (1961) On the nature of addiction and habituation. Br J Addict Alcohol Other Drugs 57(2): 73-79.

3. Kandel ER, Dudai Y, Mayford MR (2014) The molecular and systems biology of memory. Cell 157(1): 163-186.

4. Kandel DB, Logan JA (1984) Patterns of drug use from adolescence to young adulthood: I. Periods of risk for initiation, continued use, and discontinuation. Am J Public Hlth 74(7): 660-666.

5. Grant BF, Hasin DS, Chou SP, Stinson FS, Dawson DA (2004) Nicotine dependence and psychiatric disorders at the United States: Results from the national epidemiologic survey on alcohol and related conditions. Arch Gen Psych 61(11): 1107-1115. 
6. Levine AA, Huang YY, Drisaldi B, Pollak DD, Xu S, et al. (2011) Molecular mechanism for a gateway drug: Epigenetic changes initiated by nicotine prime gene expression by cocaine. Sci Transl Med 3(107): 107-109.
7. Bovornkitti S (2019) E-cigarettes ? Thammasat Med J 19: 446.

8. Bovornkitti S (2019) Tobacco harm reduction. Telemedicine \& E-health $1(5)$.

\section{For possible submissions Click below:}

